\title{
Canada's mental health legislation
}

\author{
Richard L. O'Reilly' and John E. Gray ${ }^{2}$
}

${ }^{1}$ Professor of Psychiatry, Western University, Ontario, Canada, email roreilly@uwo.ca

${ }^{2}$ Adjunct Professor of Psychiatry, Western University, Ontario, Canada
In Canada the ten provinces and three territories are responsible for their own health laws and services. The 13 mental health acts have core similarities, but there are clinically significant differences. In most Canadian jurisdictions legislation is based on common law; in Quebec, it is based on a civil code. Canadian jurisdictions favour voluntary admission and sometimes make this explicit in their mental health acts. For involuntary admission or compulsory in-patient or community treatment to be valid, three elements must be applied correctly: the process, the criteria and the rights procedures. These are reviewed in this paper.

There are 13 mental health acts in Canada because the ten provinces and three territories are responsible for their own health laws and services. Canadian mental health acts have core similarities, but there are clinically significant differences among them (Gray \& O'Reilly, 2001). All Canadian laws must conform to the overarching Canadian Charter of Rights and Freedoms, which is part of the country's constitution. In most Canadian jurisdictions, apart from the province of Quebec, legislation is based on common law; in Quebec, it is based on a civil code, as is the case in France.

Canadian jurisdictions favour voluntary admission and sometimes make this explicit in their mental health acts. For involuntary admission or compulsory in-patient or community treatment to be valid, three elements must be applied correctly: the committal process, the committal criteria and the rights procedures.

\section{Committal process}

In all Canadian jurisdictions, a physician completes the initial civil commitment certificate, which provides authority for a brief hospitalisation for assessment. All jurisdictions require that a second physician agrees that committal criteria are met if a patient is to be detained in hospital longer. Thus, in most Canadian jurisdictions committal decisions are made entirely by physicians. The exceptions are the provinces of Quebec and New Brunswick. These provinces also require that two physicians agree on the need for committal, but in Quebec the physicians must then petition a court, and in New Brunswick a tribunal, to obtain final authorisation.

When it is not possible for a physician to undertake an examination, a judge, or in some cases a justice of the peace, can order the person to be examined. In addition, a police officer may take the person to a hospital for an out-patient examination if the officer has grounds to believe that the person has a mental illness and will cause harm to him- or herself or to others. Some provinces allow a police officer to take a person for a psychiatric assessment if the officer believes the person to be at risk of mental or physical deterioration.

\section{Committal criteria \\ Definition of mental disorder}

In all Canadian jurisdictions, to be involuntarily admitted a person must have a defined mental disorder. While a formal diagnosis is not required, most jurisdictions have specific definitions of what constitutes a mental disorder. For example, the province of Alberta defines mental disorder as:

A substantial disorder of thought, perception, mood, orientation or memory, which seriously impairs the person's judgment, behaviour, capacity to recognize reality or ability to meet the demands of everyday life.

A few jurisdictions, including Ontario, retain the broad 'any disease or disability of the mind' found in the Mental Health Act in England and Wales.

\section{Harm and deterioration}

People can be admitted in Canada only if their mental disorder causes them to be likely to harm themselves or others or to suffer significant deterioration. In some provinces, the legislation specifies that the person must need psychiatric treatment. In provinces that do not have this exclusion, it is possible to detain people with untreatable disorders, such as antisocial personality disorder, although this is not common in practice.

Following trends in the USA in the 1960s and 1970s, a number of Canadian jurisdictions changed their committal criteria from a need for treatment to a risk of physical dangerousness. Subsequently, most jurisdictions added a broader 'serious harm' criterion.

Many provinces have amended their legislation to allow committal based on a likelihood of substantial mental or physical deterioration as an alternative to the dangerousness/harm criteria. Ontario has placed restrictions on the use of this provision, so that it can be applied only if: (1) the patient is incapable of making a psychiatric treatment decision; (2) the patient's substitute decision-maker agrees with the decision to treat the patient in hospital; and (3) the patient's mental disorder has previously responded to treatment.

Saskatchewan, Nova Scotia, and Newfoundland and Labrador add a capability criterion to the effect that if the person is capable of making an admission or treatment decision, he or she cannot be admitted as an involuntary patient. This is consistent with the model advocated by Dawson \& Szmukler (2006). 


\section{Rights procedures}

Mental health acts require that when patients are detained, they are informed of their rights, including the reasons for detention, the right to consult a lawyer and the right to appeal to a quasi-judicial tribunal for release. In some jurisdictions a person named by the patient or next of kin are also informed of these rights. In most jurisdictions, this information is provided by the clinicians and in some by special rights advisors.

\section{Treatment authorisation for committed patients}

\section{The right to refuse treatment}

Ontario and several other provinces give primacy to capacity. In these provinces, a person who is found capable of making a treatment decision cannot be forcibly treated even when committed to hospital. In practice, people who are capable rarely exercise this right (Solomon et al, 2009). However, procedures designed to enable an involuntary patient to challenge a finding of treatment incapacity regularly result in delays in initiating treatment (Kelly et al, 2002).

Other Canadian jurisdictions take the position that when the state takes away a person's freedom because of risk associated with a mental disorder, the state has the responsibility to provide the person with the treatment necessary to regain his or her freedom. For example, in British Columbia the medical director of a psychiatric facility provides consent for psychiatric treatment in cases when a committed patient refuses.

The three provinces which require a finding of treatment incapacity as a criterion for in-patient commitment do so as a pre-emptive approach to the quandary of detaining but not treating a patient. This is possible because these provinces use a high threshold for capacity: the person must be 'fully capable'.

\section{Advance directives}

An extension of the tension between respect for autonomy and the right to treatment is the manner in which Canadian jurisdictions deal with advance directives. In Ontario, an advance directive to refuse a treatment must be followed if it is applicable to the circumstances. Thus, individuals who state that they do not want psychiatric treatment, even if committed to a hospital, could remain in hospital for the rest of their lives unless they experience a spontaneous recovery. In some provinces, such as Saskatchewan, physicians must consider, but are not bound by, advance directives that prohibit standard treatment of psychiatric disorders for involuntarily hospitalised patients. In other provinces, such as Manitoba, the person's competent wishes must be followed by the substitute decision-maker except if doing so would endanger the physical or mental health of the patient or others. In those circumstances, the decision must be made in the patient's best interests.

\section{Consent to treatment for incapable patients}

Canada has two models for authorising treatment for individuals who lack the capacity to consent to treatment. In the 'state' model an independent appointee of the state (hospital administrator, physician, quasi-judicial tribunal or court) makes this decision, whereas in the 'private' model a substitute decision-maker, who may or may not be a relative, makes decisions for an incapable patient (Gray et al, 2008, p. 200).

\section{Compulsory treatment in the community}

Community treatment orders (CTOs) and similar mechanisms for compulsory community treatment, such as conditional leave, are now available in 8 of the 13 Canadian jurisdictions. Canadian CTOs are similar to those used in Scotland and in England and Wales. Depending on the jurisdiction, one or more physicians must complete the required forms. The process can be initiated while a patient is hospitalised or in the community. In practice, most CTOs are initiated while a patient is awaiting discharge from an involuntary admission.

In contrast to Australia, in Canada a person must have had a stipulated amount of in-patient psychiatric care before being placed on a CTO (Gray et al, 2010). For example, Newfoundland and Labrador requires that the person has been involuntarily hospitalised on three or more occasions or for a minimum of 60 days in the previous 2 years. Thus, from a policy perspective, CTOs attempt to solve the revolving-door phenomenon rather than being an attempt to adhere to the principle of using the least restrictive alternative. Alberta is the exception, as it has incorporated flexibility in its CTO provision. The basic CTO requires that the person has had two or more involuntary admissions or has had one admission of 30 or more days in hospital in the previous 3 years. Alternatively in Alberta, people can be placed on a CTO without previous hospital admissions if they have exhibited a recurrent pattern of behaviour that indicates that they are likely to cause harm or to deteriorate if not on a CTO (Gray et al, 2012).

Formal treatment planning, including family involvement, is a required part of the CTO in some jurisdictions. Furthermore, all jurisdictions require that the services necessary to support the CTO are actually available to the patient.

The introduction of CTOs has been controversial in some Canadian jurisdictions, especially in Ontario. In 2013, an application that CTOs contravened the Canadian Charter of Rights and Freedoms was dismissed by the Ontario Superior Court (Thompson v. Attorney General 2013).

\section{Other rights and safeguards}

In Canada, a person committed to a psychiatric hospital or on a CTO has the same rights and privileges as any other person except if these are specifically restricted by law. Thus, a committed person has the right to vote and to communicate with others. As noted above, patients must be 
informed of their rights when they are involuntarily detained or when determined to be incapable of consenting to their own treatment. Most Canadian jurisdictions have mandatory reviews of commitment and CTOs after a prescribed period of time. Decisions reached by these review boards may be appealed to the courts.

\section{Conclusion}

The 13 mental health acts have shared core features, but also show some important variation in the major elements. There are similarities to the provisions in many other democratic jurisdictions. The ability to challenge any provision as not being in accord with the Canadian Charter of Rights and Freedoms, ultimately in the Supreme Court of Canada, is an important safeguard against unreasonable laws.

\section{References}

Dawson, J. \& Szmukler, G. (2006) Fusion of mental health and incapacity legislation. British Journal of Psychiatry, 188, 504-509.

Gray, J. E. \& O'Reilly, R. L. (2001) Clinically significant differences among Canadian mental health acts. Canadian Journal of Psychiatry, 46, 315-321.

Gray, J. E., Shone, M. A. \& Liddle, P. F. (2008) Canadian Mental Health Law and Policy (2nd edition). LexisNexis.

Gray, J. E., McSherry, B. M., O'Reilly R. L., et al (2010) Australian and Canadian mental health laws compared. Australian and New Zealand Journal of Psychiatry, 44, 1126-1131.

Gray, J. E., Shone, M. A. \& O'Reilly, R. L. (2012) Alberta's community treatment orders: Canadian and international comparisons. Health Law Review, 20, 13-21.

Kelly, M., Dunbar, S., Gray, J. E., et al (2002) Treatment delays for involuntary psychiatric patients associated with reviews of treatment capacity. Canadian Journal of Psychiatry, 47, 181-185.

Solomon, R., O'Reilly, R., Nikolic, M., et al (2009) Treatment delayed - liberty denied. Canadian Bar Review, 87, 679-719.

\title{
MENTAL
} HEALTHLAW PROFILE

${ }^{1}$ Psychiatry Visiting Lecturer, Department of Psychiatry. University of Malta, email anthony.zahra@gmail.com 2Public Health Specialist, Office of the Commissioner of Menta Health, Mount Carmel Hospital, Attard, Malta

${ }^{3}$ Commissioner for Mental Health and Older Persons, Mount Carme Hospital, Attard, Malta

\section{A new Mental Health Act for Malta}

\author{
Anthony Zahra, ${ }^{1}$ Miriam Camilleri ${ }^{2}$ and John Cachia $^{3}$
}

\begin{abstract}
Until recently, the care of persons with mental disorder in Malta was regulated by mental health legislation enacted in 1976. This was closely modelled on the 1959 British Mental Health Act. Now, the Mental Health Act 2012 is being implemented in two steps, in 2013 and 2014. The paper reviews its provisions.
\end{abstract}

The Maltese islands constitute a small independent country, a member state of the European Union since 2004, with a population of around 420000 (National Statistics Office, 2011). Until recently, the care of persons with mental disorder was regulated by mental health legislation enacted in 1976. This was closely modelled on the 1959 British Mental Health Act (Saliba, 1994), focused on setting out formal procedures to be followed within mental healthcare provision.

The Mental Health Act 2012 was in development for over a decade; it is being implemented in two steps, in 2013 and 2014.

The Act has 11 parts, each comprising several articles. Its main aims are presented within the short title, 'an act to regulate the provision of mental health services, care and rehabilitation whilst promoting and upholding the rights of people suffering from mental disorders'. Such explicit expression of the principles guiding the legislation is a significant departure from the prescriptive nature of the previous law.

This paper outlines the more salient changes that have been introduced, following the structure of the Act itself.

\section{Part I: Preliminary}

Part I focuses on operational definitions of terms used within the Act. The new terminology used in this law reflects the division between clinical and managerial responsibility within mental healthcare facilities, recognises the contribution of all professions working in mental healthcare, removes stigmatising terminology and provides a more clinical definition of 'mental disorder'. Mental disorder has been defined as a significant mental or behavioural dysfunction exhibited by signs or symptoms including disturbance of thought, mood, volition, perception, cognition, orientation or memory, and deemed pathological in accordance with internationally accepted standards. Treatment has been defined as being medical, nursing, psychological and social, implicitly following the biopsychosocial model (Engel, 1980), and is a core component of care as defined by this law.

\section{Part II: Rights of users and carers}

The rights of persons with mental disorders and their carers are clearly stated. Treatment is to be delivered in the least restrictive manner and setting, with an emphasis on having treatment delivered primarily within the community. The law also sets out the principles of active participation of the patient in the planning of care, adequate information about the disorder, treatment options and services available, free informed consent, confidentiality, access to clinical information, free and unrestricted communication with the outside world and the right to receive visitors in private within all reasonable times. 